CHAPTER 5

\title{
State, Netocrats and the Commons: Developing a Cultural Policy in the Era of Platforms
}

\author{
Prodromos Tsiavos
}

\section{Setting the scene}

The question of how we see antiquities is not merely a sensory or factual question; ${ }^{40}$ it is equally an existential, political as well as socially constructed and technologically mediated question. It is also a question that cannot be answered at the individual but rather at the collective level. ${ }^{41}$ More than anything else, it is a question that while it may not define, it at least influences the way in which we handle, reproduce, and exist in relation to (cultural heritage) objects (Harman 2018).

An Athenian of the Ottoman period would incorporate an antiquity into his house; an Englishman doing the Grand Tour at the same time would bring some antiquities back home; a Greek political exile in Makronisos in the 1950s

${ }^{40}$ For a detailed discussion of the issue see Hamilakis 2013.

${ }^{41}$ Hamilakis (2007: 15-17) explores in detail the Anderson's (Anderson 2006) argument in relation to the role of imagined communities in the process of nation formation.

How to cite this book chapter:

Tsiavos, P. 2020. State, Netocrats and the Commons: Developing a Cultural Policy in the Era of Platforms. In Lekakis, S. (ed.) Cultural Heritage in the Realm of the Commons: Conversations on the Case of Greece. Pp. 109-126. London: Ubiquity Press. DOI: https://doi.org/10.5334/bcj.g. License: CC-BY 
would be forced to build replicas of the Parthenon while confined in a concentration camp; an archaeologist in the 1970s would meticulously document and publish his excavation findings; ${ }^{42}$ a film director or a researcher in the 2000s would request permission from the Central Archaeological Council in order to film or publish pictures from ancient Greek monuments; a Chinese tourist or a Greek pupil in the 2010s would search for the Acropolis in Google and Wikipedia before visiting them and share their pictures over Facebook and Instagram during their visit.

Antiquities live a rich, long and multifaceted life. Their sociomateriality ${ }^{43}$ is subject to a continuous and rhizomatic transformation process that renders them continuously negotiable and contested, but also central to the collective imagination of the communities they relate to. There is a growing body of research exploring how antiquities constitute sociomaterial agents that form and are formed by the nation state. In this intellectual context, the way in which antiquities are seen, reproduced, surrogated, transformed and disseminated, becomes a question not merely relevant for the antiquities themselves but also for the modern nation and the multitude of its evolutionary trajectories.

The centrality of the antiquities and their core role as a device supporting the collective imagination of the nation state is astutely reflected in the provisions of the Greek Archaeological Law (Law 3028/2002), ${ }^{44}$ particularly the sections regulating access, reproduction and the dissemination of such reproductions (Law 3028/2002: A. 46). It is in these provisions that we may identify in the clearest fashion the effort of the nation state to control not just the materiality of the antiquities, but also their symbolic dimension by setting conditions for their reproduction and imposing terms on how such reproductions are to be disseminated and published. Especially with regards to the latter, the law

${ }^{42}$ For an analysis of these examples see Hamilakis 2007.

43 "Going forward, we suggest that further work is needed to theorize the fusion of technology and work in organizations, and that additional perspectives are needed to add to the palette of concepts in use. To this end, we identify a promising emerging genre of research that we refer to under the umbrella term: sociomateriality. Research framed according to the tenets of a sociomaterial approach challenges the deeply taken-for-granted assumption that technology, work, and organizations should be conceptualized separately, and advances the view that there is an inherent inseparability between the technical and the social" (Orlikowski \& Scott 2008: 434). For an extensive overview of the concept of sociomateriality see (Scott \& Orlikowski 2013; Orlikowski \& Scott 2008).

${ }^{44}$ In this essay we focus solely on the Greek Archaeological Law 3028/2002. However, since the main elements of the Greek Archaeological law may be found in other jurisdictions (Morando \& Tsiavos 2011), the main argument presented in this paper may be applicable in different contexts as well. 
makes a series of assumptions in relation to the media landscape that is formed by the devices used to capture and reproduce the antiquities into surrogates. These assumptions extend to the mechanisms, infrastructures and institutions used to edit, reproduce and disseminate the outcome of the capturing process.

This process of translation of the technological landscape, the media technoscape of reproduction and dissemination, is not one that can be taken at face value. As Latour outlines, "there is no transportation without transformation" (Latour 1996: 119) ${ }^{45}$ and in the case of the Greek Archaeological Law, only a fragment of technological methods have been legislated for in the Greek legal system. However, when one attempts to apply these provisions in a world that is technologically substantially different, a series of failures emerge. These are not merely failures of enforcing the law, but rather failures of enforcing the broader programme of a state-controlled building of the collective image of the nation-state.

It is important to highlight the two aspects of our main argument:

First, we maintain that the failures in the enforcement of the Archaeological Law are not merely instantiations of the classic problem of legal regulation trying to keep up with technological developments. Instead, we argue that these failures are rather the expression of a much deeper phenomenon: that of the clash between two distinct but very powerful forms of regulation, law and technology. These have different institutional pedigrees but compete with increasing force for dominance over the regulatory space of the nation-state. Thus, the regulation of antiquities, as a form of cultural heritage, becomes a symbolic arena within which the drama of regulatory competition between law and technology unravels.

Second, by "opening the black box of technology" (Winner 1993) and looking into the families of technologies that dominate the collective production of meaning, we are faced with the difficult question of cultural heritage policy making in a world of polycentric regulation. While this is normally posed as a question of how to tighten forms of hierarchical control of content dissemination, we argue that there is a need to devise strategies that take into account the dominance of new forms of digital and symbolic production. These are paradigmatically expressed in the netocratic ${ }^{46}$ model of digital platforms and the

45 "In the translation model, there is no transportation without transformation-except in those miraculous cases where everybody is in total agreement about a project" (Latour 1996: 119). See also Schmidgen on Latour: "At the same time, Latour's insistence on transmission as change can be read as a paraphrasing of an insight of the literary scholar and media theorist Marshall McLuhan: "Each form of transport not only carries, but translates and transforms, the sender, the receiver, and the message (McLuhan 1994: 90)" (Schmidgen 2014: 4).

46 While the term "netocracy" and "netocrats" has been used by Alexander Bard and Jan Söderqvist (2002) in juxtaposition to "consumariat" in order to express the global upper class that is based on high-tech to draw global 
sharing economy vis-à-vis the model of commons and peer based production (Benkler 2002; 2006).

Hence, the question of devising a national cultural heritage policy inevitably needs to take into account the fact that that the law is not the only, nor even the most powerful form of regulation. Moreover, classic hierarchy or control and command models of regulatory intervention (Baldwin et al. 2012) are not necessarily the optimum models for serving the objectives of a national narrative on cultural heritage, since sharing economy platforms and the commons dominate both material and immaterial modes of production. At the end of the day, the failures of classic regulatory intervention raise deeper questions over ownership of the nation state and the need to translate a plural, open and commons-based form of national identity into regulatory forms able to resist the ultranationalist, sectarianist and monocultural models of nationalism that digital platforms more often than not invite.

This paper is structured in the form of 'episodes', that is, snapshots of different artefacts, instances or technologies that highlight various facets of the phenomenon of the interaction or clash between the state, the commons and the netocratic platforms that allow us a better understanding of the framing within which contemporary cultural policy is formed and enacted.

\section{Ways of seeing}

How can we see the Parthenon today? The process of seeing a monument in our highly mediated society is one that starts before we even approach an antiquity. If we want to know what it is that we are going to visit, then we will search for it on Wikipedia. More precisely, we would carry out a Google search, which in all likelihood will provide us with Wikipedia as the primary source for a particular monument. Even if the relevant Wikipedia entry is not the first search result we get, it is from Wikipedia that the Google search results obtain the data necessary to provide us with an abstract of (a) what the Parthenon is; (b) where it is; (c) how to get there and the times during which we can visit it; (d) other related places and information that other individuals have searched, including images and critiques. The search will most likely be carried out on a mobile phone rather than a desktop or laptop and sometimes it might be during or after the actual visit.

The use of technologies to create representations or reproductions of antiquity is not new. There is a considerable body of literature on the subject of the use of photography as a means of constructing the image of antiquities in

power and domination. Our use of the term is to denote a wide range of platform (Gawer 2009) technologies that are based on crowdsourcing (Surowiecki 2005) or community type of activities in an extractive and exclusive manner. 
tandem with the objectives and collective imaginary of the artist or society that produced such images (Derrida 2010; Szegedy-Maszak 2001). Similarly, representations of antiquities in paintings operate again as a device to represent the collective imaginary related to antiquities. In addition, once the fixation of the images is completed, the image itself demonstrates an agency, contributing to the collective imagination it chooses to serve. We need only look at the paintings of the Acropolis by the pre-Raphaelites, Nelly's images of Mona Paeva at the Acropolis, the representation of the Acropolis in images of the early $20^{\text {th }}$ century or at the images on contemporary postcards and in textbooks. We could also look at the images of the Acropolis found on Facebook, Instagram, Flickr and Wikimedia Commons.

It is important at this stage to note that an approach to the images as something that stands alone as an artefact is extremely misleading. In order to unravel the Ariadne's thread that leads to an understanding of the framing that an image creates, it is necessary to appreciate it within the broader institutional ecology and dissemination system in which it exists. Nelly's images, for example, were shot to be published in the French magazine Illustration de Paris and then disseminated through a market system and a supply chain that involved the publisher, the printer, a dissemination network and shops where people could buy the magazines. We also need to appreciate that the consumption pattern of the magazine was such that it encouraged individual reading or sharing of the physical artefact of the magazine. Finally, those pictures had an afterlife as artworks, parts of the Benaki archive and private collections as well as through exhibitions and events, but also by being re-photographed digitally and placed in circulation anew over the internet.

The patterns of production and consumption of an early $20^{\text {th }}$ century photograph differ substantially from the bulk of photography as it takes place today. The main difference is not merely the ease with which high quality photographs may be taken or the post-production that is possible today. These are important parameters that, as Manovic (Scott \& Orlikowski 2013; Orlikowski \& Scott 2008) has extensively explained, are framing - if not defining - our aesthetics and understanding of the represented subject. However, what makes the pictures we see on the internet substantially different from everything we have seen in the past is the whole life-cycle of their production and dissemination as well as the mass of the collections of which they are destined to become part of. The introduction of photographs on social media, initially with Facebook, Flickr and Pinterest, but particularly with Instagram has marked an entirely different form of representation: one that is both massive and relies to a large extent on the self-image or 'selfie culture', one that introduces a particular type of frame and filtering of the image through predefined options and one that is followed by - again - a predefined set of reactions or 'impressions' by other participants to those social networks that constantly assess and evaluate the image, the photographer and the humans and non-humans represented on those pictures. In addition, once the photograph is taken it is then placed in a 
rhizomatic (albeit well defined by algorithms) flow of information on multiple social media platforms and of course the almost unique access point for World Wide Web, i.e. the Google search engine. As such, the photograph becomes part of a massive and algorithmically mediated collection that begs for interpretation not as an isolated item but as part of a much greater, dynamic and controlled whole.

This framing of the image is quite different from what happens in the case of images contained in Wikipedia and Wikimedia Commons. The inclusion of an image in this context once again follows specific rules with regards to the technical specifications of the picture. However, the objective here is quite different: it is not the sharing of a personal moment but rather the search for objective or collectively accepted facts. As such, Wikipedia seeks to both present encyclopaedic entries following a very rigorous set of rules as to what is acceptable or not and to respect the rules regarding the provenance of the images uploaded, so that they conform to copyright and cultural heritage protection rules. In addition, the content found on Wikipedia and Wikimedia Commons is constantly and collectively edited and checked, through a set of common and transparent rules. Finally, this is content that, again, is part of a massive collection constituting the most commonly accessed form of factual resource on the Internet.

This digital ecosystem produced through different forms of mega-platforms, whether Google, Facebook and Instagram or Wikipedia, invites a form of image production and consumption that differs substantially from forms of picture taking we have seen in the past. It departs from picture taking of the past on at least four points. First, the technological framing of the picture in terms of specifications, filters or framings that the technological interface itself imposes. Second, it is an activity that happens through mobile devices throughout the life-cycle of a visit to an antiquity or its representation. Third, it is highly connected, interactive and collective irrespective of whether it is a personal story or the effort to construct a collectively acceptable fact. Fourth, the picture is experienced as part of a massive collection that is algorithmically mediated and thus made accessible to the recipient of the picture in ways that are not always transparent to the end user.

\section{The State of the Law}

No matter how appealing it may be, there is no such thing as a technology neutral law. The idea of drafting laws that focus on 'naked' human activity, stripped of any technological context has always been the Holy Grail for legislators and policy makers. However, it has also been an almost impossible task. Laws embody representations of technology precisely because they rely on technology's regulatory capacity to achieve their normative programme. Lessig, in his classics 'New Chicago School' (1998) and 'Code and other laws of cyberspace' 
(1999), demonstrated with great clarity that laws, technologies, markets and norms not only interact but that such interactions are the essence of the contemporary regulatory landscape. In societies heavily mediated by technology, understanding the way in which such interactions between different modalities of regulation take place is an essential precondition for assessing the effectiveness and efficiency of both regulation and its underlying policies.

Law 3028/2002 is a classic case of a law that contains technological assumptions. This is particularly clear in the case of the Ministerial Decrees, based on the Archaeological law. These decrees ${ }^{47}$ provide the detailed conditions for granting permission to access, reproduce and disseminate the reproductions of antiquities, found both in archaeological sites and museums. The representation of technology is most clearly illustrated in the different categories of acts of reproduction and dissemination that focus on specific types of media. What is even more interesting, is that the law also reflects different conceptualisations of how the market operates in relation to the circulation of reproductions of antiquities. More specifically, we may identify the following elements:

-Access to archaeological sites is divided into access solely for viewing and access for the reproduction of the archaeological artefact.

-Reproductions of the archaeological artefact are again divided into reproductions that are conducted with the use of 'professional equipment', for which a fee is required and other reproductions, for which no fee is required.

-Similarly, there are further categorisations of reproductions with reference to paper and electronic publications, dissemination through broadcast and internet technologies, reproduction for postcards, records, CDs and DVDs, labels, rubber stamps, leaflets, packaging, electronic cards, logos etc.

-Another element that also appears is that of profit, direct or indirect, particularly in relation to the dissemination of the reproductions. Similarly, the fee for the production of an audiovisual work is calculated on the basis of the costs of its production.

- There is a fee waiver in any case where the photography or video recording is used for the documentation of excavations and is conducted by the excavators or the researchers and where the funders have received the necessary licenses for the publication of the results. The fee is also waived when it takes place for purely academic and scientific purposes, such as teaching and documenting archaeological work. Finally, the fee is waived when it relates to a production of the Ministry of Culture and Sports.

-Accordingly, there is a waiver in the case of the use of reproductions, photographic and audiovisual, whose uses fall within the scope of the

47 See Government Gazette (FEK) B' 1138/10.04.2012; Government Gazette (FEK) B' 648/7.3.2012; Government Gazette (FEK) B' 3046/30.12.2011; Government Gazette (FEK) B' 1491/27.10.2005. 
Copyright limitations and exceptions, for publications of EU educational establishments, for limited editions by researchers and research institutions that serve and are addressed to the academic community, for $\mathrm{PhD}$ and postgraduate publications, for solely academic publications of the Greek Research Performing Organisations and The Archaeological Society at Athens, and for all the Ministry of Culture publications.

There are some clear technological and market assumptions in the Greek Archaeological Law:

- The distinction between amateur and professional photography is mostly based on the equipment and its technological capacities. However, as technology advances, technological features that previously could only be found in professional equipment are now present in almost every mobile phone. Similarly, certain types of digital capturing, such as aerial photographs and videos, while requiring permission, are increasingly taken by nonprofessionals, using portable devices or mini drones.

- Another criterion to assess whether a fee is required for the taking of photographs or video and their respective distribution is the direct or indirect flows of monetary value. Again, this is a classic market model, where the producer of the content or a distributor/disseminator that the photo producer contracts, gains revenue from the process of distributing the picture.

- The main technological/market assumption is that the dissemination of the content occurs through publishing, broadcasting or film dissemination. This means that the controlling mechanisms put in place by the law mostly focus on the dissemination intermediaries that are required to obtain the necessary permissions every time an act of publishing or distribution takes place.

While these three assumptions make sense in an environment of centralized and formalized collection and distribution of physical or digital surrogates of the antiquities, it makes little sense in a sharing economy or commons-based environment:

- The model of professional vs. amateur photo shooting is one that is difficult to assess since both the quality of equipment and monetary criteria are hard to establish.

- The model of revenue making as a criterion for providing a fee becomes one that is either not easy to enforce or requires specific sets of agreements. In the case of social media platforms, the person taking the picture is not the one that profits from it. While there is a heated legal debate as to the status of such providers, it is still accepted that they are Information Society Providers (ISPs) and as such they are not liable for the content trafficking 
over their networks. Increasingly, however, they are required to put in place mechanisms to both ensure that the content uploaded is clear of any third-party Intellectual Property Rights (IPR) and General Data Protection Regulation (GDPR) compliant. This means that there is potential opportunity to impose similar conditions regarding the regulation of antiquities. However, this means that there must be special agreements between the social media companies and the state as how to deal with the dissemination of such content.

- The current system is built on the assumption of a single act of redistribution per licence from the Ministry of Culture. However, this is not how commons-based transaction operate. In the case of Wikipedia, for instance, there is a serious problem in relation to the operation of the licensing regime. The Creative Commons Attribution ShareAlike licence used by Wikipedia and Wikimedia Commons, where most photographs will be uploaded, allows for the downloading, creation of derivative works and redistribution of the work. As a result, while there may be a licence from the Ministry of Culture regarding the original uploading of the material on Wikipedia and its distribution from that point, additional licensing would in principle be required for the subsequent re-publishing and re-distribution of the same picture, as it would constitute a new act of dissemination. This would entail an endless chain of requests for licences from the Ministry or would render all Creative Commons Licences illegal.

-The reference to the Copyright notice as well as the limitations and exceptions as a means for not requiring a fee is rather problematic. The statement "copyright Ministry of Culture", which is a requirement for all images captured and disseminated by an applicant, would seem to imply the acquisition of copyright by the Ministry of Culture as a condition to provide a licence for accessing the content. While the use of real property as a mechanism for obtaining rights over the digitised surrogate is not a new phenomenon, it creates substantial enforcement issues. Moreover, the provision stipulating that the fee is waived in the case of uses falling under the limitations and exceptions of Greek Copyright law ${ }^{48}$ is equally problematic. On the one hand it makes reference to a very limited set of uses that in most cases would not satisfy the needs of the person capturing the images. On the other hand, it would still require permission from the state in order to engage in such uses, something that would run contrary to the spirit and function of the limitations and exceptions mechanism, which is precisely intended to avoid the transaction costs of obtaining a licence.

-In order to obtain any of the required licences, it is necessary to go through an application process that is mostly off-line and requires a decision making

${ }^{48}$ See Law 2121/1993: A. 18-28C, Copyright, Related Rights and Cultural Issues Government Gazette (FEK) A' 1993. 
process per application by the Central Archaeological Council (KA $\Sigma$ ) (Law 3028/2002: A. 46 \& 50). This imposes high transaction costs that, while they make sense in the context of professional reproduction and distribution, make little sense in the case of private use of content.

Overall, the clash between the provision of the Archaeological Law and the technological, market and licensing reality of the sharing and commons-based economies is evocative of the huge dilemma the Ministry of Culture is faced with. On the one hand, it could technically still try to implement the Archaeological Law provisions, by forcefully requiring the obtaining of all types of licensing and issuing cease and desist notices. The lack of control in the use of images of antiquities, as well as the loss of revenue are evident. However, the question of how to mitigate such losses remains open. A strategy of enforcement of the current regime may be highly problematic. It would not only entail substantial costs and require resources that the Ministry is doubtful it could spend, but it is also questionable whether such tactics would support the primary objectives of Law 3028/2002, namely the promotion of Greek culture, the protection of antiquities and the promotion of the image of Greece as intertwined with the antiquities in a continuous spectrum ranging from the prehistory to today.

\section{Owning the Law}

A first response to the inability of Law 3028/2002 to keep up with the changes in the technologies of capturing and digitally distributing surrogates of protected antiquities would be to amend the law so as to reflect more accurately the technological and market landscape of our times. While this is a reasonable response, it would only patch the problem. It would address its symptoms rather than its actual causes and, hence, obfuscate rather than resolve the problem.

An underlying assumption behind the Archaeological Law, as indeed behind most of our laws, is that law maintains the hegemony within the regulatory ecosystem. As we know from a range of regulatory theorists, from Easterbrook (1996), and Lessig $(1996$; 1998) to Brownsword $(2005 ; 2006 ; 2008)$ and Black $(2000 ; 2001 ; 2002)$, regulation is increasingly dominated by other forms of regulation, mostly technologies and the markets they sustain. It is the immediacy of technology as a regulatory form and its enforcement, unmediated by social meaning that renders it a supreme regulatory force, more often than not dominating the regulatory environments where the state is dwarfed by the techno-economic power of the originators of the technology. In addition, it is the characteristics of netocratic technologies, mostly sharing economy platforms, that enable them to exercise an almost irresistible force over the regulated subject and hence turn law into a second order if not insignificant source of regulation. 
Platforms have some key characteristics that both accelerate and intensify their regulatory features. For example, when a search is made through the Google search engine, it is drawing from the collective experience of all previous searches ever made on this keyword before. In other words, it draws from and contributes to a form of commons that operates temporally and cyberspatially: it is affected and affects all searches that have ever been made. At the same time, it is also affected by the history of searches, the location of the individual and the other uses of services they have made in the past, as well as by Google's own confidential algorithm. In a sense, it contributes to a public and to a personal commons, but at the same time the mechanics of these commons and its constituting governing mechanism remain by and large opaque. Most importantly the ranking of the search is monetized by Google and sold as a service to third parties. In this sense, there is a degree of extraction that draws from the commons and nullifies them at the same time: it is commonsbased, since it requires the collective interactions in order to draw the data that constitute the blood in the veins of the Google ecosystem; and it is extractive as it keeps sucking data produced by and large by all types of human activity, both individual and collective, it can lay its digital hands on. The more humans use Google's apps and services, the more the algorithm is fed with their data and provide services that are better and hence may attract more users.

This symbiotic relationship, which makes Google a counter-rival good, i.e. a good whose value increases with its use, is at the heart of its regulatory force. It is not merely the immediacy of the technology that only allows the user to follow its predetermined path, but it is the gradual incapacitation of the user to opt for another service, because of the network economics that makes Google a much more powerful regulator compared to the law: Google is a textbook example of the 'There Is No Alternative' dictum.

To make things even worse, the law and particularly the Archaeological Law has to face other forms of inevitabilities as well: the dominance of Google as a search engine and as a gateway to access the web makes any other distribution system subservient to it. The regulation of a digital publisher is relevant only after it is spotted by the user and Google controls its findability.

The case of most of social media platforms is pretty much the same, though the control they exercise over the search and display of results is much greater than that of Google's: it is not only the search and display algorithm they control, but the entirety of the environment. The extraction here is much more unhindered and the devices of control much more obscure. In fact, both in the case of Instagram and Facebook, the revelation of the mechanisms of searching and displaying, i.e. the basic operation of the algorithm, is only revealed to the extent it is necessary to fulfil the respective corporate programme of action.

It is necessary here to ponder a bit more on this aspect of controlled revelation. 
The items that remain in the commons on these platforms are mostly third party content or more specifically hyperlinks to the URIs of third party content, plus a minor contribution by the end user in the form of either a search (as is the case of Google Search) or a comment/ post (as is the case in social media). It is the collective and individual choices of content over time that are shared but, as we have seen, in a rather filtered way: the result of these contributions, the digital information commons that is created from these choices and actions is not shared with everyone or with the same terms. It is the information asymmetry that characterizes netocracies, which is expressed in a three tier pyramid: at the top there are the owners of the platform who extract the entirety of the information and use it as they wish; at the middle layer there are the commercial users who buy aggregate information, usually packaged as a service, as well as the way in which information is displayed to the end user; at the bottom of the pyramid are all the users whose activity, including even biodata, is continuously harvested in order to produce value for all three layers of the pyramid. The flows of data and value are inverse: the users provide all the data and get a minimum of value, the professional users are buying data and attention and provide some data and the netocrats obtain both data and monetary value and they offer as a service the platform that produces value for them.

The revelation of the workings of the algorithm has a regulatory quality: as the professional users are instructed as to the operation of the algorithm, they alter their behaviour in order to correspond to its function and maximise the value produced for them, mostly to maximise the exposure of their products and services and achieve specific results (e.g. tickets, purchases, views, interactions etc.). The user is also instructed as to how the algorithm operates through the use of the service and adjusts their behaviour accordingly, e.g. by altering the nature of the posts in order to achieve the impressions or the following they desire.

Such is the totality of these platforms that there is very little space left for the law to operate. This is apparent in the ways in which search results that rank and are depicted on Google or hashtags operate in the context of social networks. How can the State achieve control of the collective imaginary through the control of the dissemination of image(s) of antiquity, when the distribution network is totally outside its control? How is it possible for the law to retain its regulatory supremacy when the state from which it derives its power is in the best-case scenario positioned only at the middle layer of the netocrats information/value pyramid? How can the state be seen as the hegemonic source of regulation, when it struggles to increase its ranking in Google search results or appear in hashtags the production and value of which it does not control?

\section{Rhizomes of Regulation}

Appreciating that the regulation of the making and distribution of images of antiquities is positioned within a polycentric rather than a state-driven 
environment is perhaps the first and most important realisation required for the development of a consistent cultural heritage policy. This is not just a question of how to regulate a set of technologies, but rather how to interact with another source of regulation that is, if not of more, then at least of equal power.

The particular regulatory features that platforms have make them a particularly strong regulatory source, with their own programme of action and enforcement tools. This is not something that has evaded the attention of policy makers and legislators. While platforms in their original form have been exempted from liability, especially in the context of Intellectual Property Rights, through the World Intellectual Property Organisation (WIPO) treaties (Adams 1997) and the e-commerce Directive (European Parliament and The Council 2001), there is increasing discussion as to whether we need to reconsider such legislation in order to exercise a greater form of control over them. This is an interesting trend, since it marks a transition from a generation of legal instruments that saw Internet Service Providers as private sources of enforcement and encouraged them to create their own mini-regulatory regimes in order to handle primarily IPR infringements in return for their lack of liability to a new generation of laws that sought to increase their level of liability and position them within the regulatory regime of the law.

The recent draft Copyright Directive (European Commission 2016) is an example of such an approach: it imposes upon platforms the obligation to clear any content before it is uploaded on their servers, especially when it is then shared by its users. This kind of legislation explicitly acknowledges, first that the value created for platform owners stems from the sharing and interactions of their users and that these, in turn, are facilitated by the content they share. Hence, the draft copyright directive argues, there must be some sort of revenue sharing of the platforms with the original owners of the material. This approach reflects the value structure of the European economy, which is much stronger in content creation compared to platform ownership, is also a clear appreciation of the regulatory strength of platforms as well as an effort to combine the State's regulatory programme of action with that of the platforms: if the latter wish to lawfully extract value from users, then, first, they need to share revenue with the content owners and second, submit to the regulatory force of the state regulators by increasing their liability.

This is not an isolated regulatory intervention. We have seen similar types of regulatory responses in cases such as Uber, where it is obliged to conform to labour and transport regulations, AirBnB in terms of paying city taxes and collaborating with the tax and planning authorities and all social media platforms in relation to their compliance with the GDPR. What is common in all of these cases is the tacit appreciation of the regulatory force that these platforms have, the concerted effort to make them comply with the rule of law and the aim to protect the relevant industries and markets that are threatened by the rise of the techno-markets that platforms constitute. What is also common in all these efforts is that they are most successful when they occur at a mass scale level 
that goes either beyond the nation state (e.g. the EU) or involves mega-national jurisdictions, such as the US or China. In all of these cases scale matters in order to be able to meaningfully negotiate with platforms that have hundreds of millions of users and budgets that surpass those of an average nation-state. Size, here, matters precisely because of the market that brings with it and the regulatory capacity that they themselves carry.

However, this type of approach means that a country the size of Greece can only operate in terms of its cultural policy response within the framework of the regulatory tools and policy framework of the EU. Any intervention that is solely local and does not in one way or another bootstrap on the EU level is destined to fail or have the exact opposite effect. For instance, a regulatory response banning pictures of the Acropolis from Google or Instagram, is not really possible in terms of enforcement costs. In this case, the individual users would have been targeted and it would be almost impossible to defend it legally in all the jurisdictions solely by means of Greek legislation.

This is, of course, not a source of major surprise. Even in the case of the regulation of classical antiquities, while the content of it remains in the competency of the Greek state, it is hugely influenced by other policies, mostly financing, infrastructure and environmental policies. The way in which funding is channeled for most restoration works is through the Greek Regional Authorities and the Ministry of Development, following the regulatory framework and priorities of the Greek Partnership Agreement (Partnership Agreement 2016) as approved by the EU. In a practical sense this means that the funding, which operates a form of signaling and hence regulation for the state agencies and services, again does not stem directly from the Archaeological Service, nor is it possible to be seen as a purely sectoral or isolated Greek policy.

Similarly, a new cultural heritage policy for global mega platforms can only be seen and implemented in the framework of the broader EU platform policies (Goudin \& European Added Value Unit 2016). This 'Cost of Non-Europe' study examines the current economic, social and legal state of play regarding the sharing economy in the European Union, and identifies the cost of the lack of further European action in this field. The assessment of existing EU and national legislation confirms that there are still significant implementation gaps and areas of poor economic performance. The subsequent examination of areas where it was believed that an economic potential exists highlighted that substantial barriers remain, hindering the achievement of the goals set out in the existing legislation. Moreover, some issues are not or are insufficiently addressed (e.g. status of workers employed by sharing economy service providers and in the same way that it acted in relation to Copyright law almost two decades ago, it needs to do the same now understanding this as a horizontal rather than sectoral policy. It needs to focus on developing strategies of regulation and negotiation with mega platforms emphasizing liability, licensing of operation, reporting and flow of value to the Archaeological Service. 
Another policy trend which is of equal value and importance is the dual practice of supporting and encouraging the free flow of data while regulating it in order to conform to the policy objectives of state or super-state regulators. Such policies appreciate the need to increase the flow of data with the minimum transaction costs, while ensuring that the state regulatory programmes are respected and advanced. The EU Digital Single Market (DSM) policies (European Commission 2017) are an exemplary case of this trend, particularly the initiatives related to the building of European Data Economy, such as the PSI Directive, the Regulations for the Free Flow of Personal and non-Personal Data, the European Open Science Cloud and the Communication "Towards a common European data space". All of these policies and regulatory measures have as an underlying assumption the need to increase low transaction cost flows of data within the European Union, while ensuring that the services offered by non-EU providers conform to the policies set out by the regulators with respect to IPR ownership, confidentiality, personal data protection, competition law rules and other sectoral legislation.

While such regulations that increase the flow of data are necessary for the development of most of the services provided by the mega platforms and in that sense eradicate the regulatory power of the state, at the same time they are essential for the existence and growth of the commons. It is in this growth of the Commons, as expressed in Wikipedia and Wikimedia Commons, Free and Open Source Software (FOSS) or open scientific content that the state will be able to produce or cultivate its narrative: by providing access to the monuments for which it is the custodian and allowing for their reproduction with conditions of proper referencing as well as of further sharing of the surrogate on the same terms and conditions as the original surrogate.

These conditions allow for the maximum circulation of the work, which reinforces the narrative of the producer of the picture while ensuring referencing to the locus of the creation of the collective imaginary, that is the state. Even in the case of extractive platforms that own the regulatory habitat within which their users interact and produce value, there is still a communication and interaction commons that the platform uses in order to extract value from the users, whereas the state could use it in order to support the types of meaning and symbolic value it wishes to promote.

This requires a set of regulatory devices and techniques that are substantially different from the ones now at hand: it is essential to focus on maximizing access to digital surrogates with proper referencing at a close to zero transaction cost rather than broad prohibitions of access with limited interest on how referencing is effected; to seek moderation and instigation in the production of meaning through working with communities rather than approving and controlling access to space and content; to negotiate at all possible levels with netocrats, while always attempting to deploy the EU policy toolkits and frameworks; to appreciate and accept the regulatory power of mega-platforms and 
hold them liable for the actions which are monitored and are taking place over their platforms; to appreciate the role of the materiality of the monument and the interplay of the monument with local communities, the civil society and the markets in order to increase the leverage against the netocrats.

The existence of a polycentric regulatory landscape (Bell 1991/1992; 1998) signifies the transition of the function of regulation from a means of state policy implementation to a domain of conflicting or colluding regulatory regimes and modalities. While the regulatory positioning of platform technologies, is clearly privileged in a techno-market driven context, the nation-state, supranational formations like the EU or mega-jurisdictions such as the US or China are likely to reassert their regulatory role through the concentrated targeting of the netocrats at all possible levels. This reaction, which we have seen forcefully and under different strategic models in the US, China and the EU, is likely to become more consolidated in the future. As the regulatory wars saga unravels, the positioning of small/medium states, such as Greece, that still wish to form a national rhetoric can only be sustained within the broader regulatory formations that envelope their action. Whether their control of images as a form of control of the collective imaginary of the nation community will persevere remains an open question. The only certainty is that the battle for regulatory dominance has just begun; and the state is not the only game in town.

\section{Bibliography}

Adams, J. N. (1997). WIPO: Intellectual property. European Intellectual Property Review, 19(4), 113-116.

Anderson, B. (2006). Imagined communities: Reflections on the origin and spread of nationalism. London, United Kingdom: Verso.

Baldwin, R., Cave, M. \& Lodge, M. (2012). Understanding regulation: Theory, strategy, and practice. New York, NY: Oxford University Press.

Bard, A. \& Söderqvist, J. (2002). Netocracy: The new power elite and life after capitalism. London, United Kingdom: Reuters/Pearsall.

Bell, T. (1991/1992). Polycentric law. Humane Studies Review, 7(1). Retrieved November 20, 2019, from https://theihs.org/w91issues/.

Bell, T. (1998). Polycentric law in the new millennium. Retrieved November 20, 2019, from http://www.tomwbell.com/writings/FAH.html.

Benkler, Y. (2002). Coase's Penguin, or Linux and the nature of the firm. The Yale Law Journal, 112, 369-446.

Benkler, Y. (2006). The wealth of networks: How social production transforms markets and freedom. New Haven, CT: Yale University Press.

Black, J. (2000). Proceduralising regulation: Part I. Oxford Journal of Legal Studies, 20(4), 597-614.

Black, J. (2001). Proceduralising regulation: Part II. Oxford Journal of Legal Studies, 21, 33-58. 
Black, J. (2002). Regulatory conversations. Journal of Law and Society, 29(1), 163-196. DOI: https://doi.org/10.1111/1467-6478.00215.

Brownsword, R. (2005). Code, control, and choice: Why East is East and West is West. Legal Studies, 25(1), 1-21.

Brownsword, R. (2006). Neither East nor West, is mid-West best? Script-Ed, 3(1), 15-33. DOI: https://doi.org/10.2966/scrip.030106.15.

Brownsword, R. (2008). Rights, regulation, and the technological revolution. Oxford, United Kingdom: Oxford University Press.

Derrida, J. (2010). Athens, still remains: The photographs of Jean-François Bonhomme. New York, NY: Fordham University Press.

Easterbrook, F. H. (1996). Cyberspace and the Law of the Horse. University of Chicago Legal Forum, 207-216.

European Commission. (2016). Proposal for a directive of the European Parliament and of the Council on copyright in the digital single market, Pub. L. No. COM(2016)593. Retrieved September 7, 2018, from https:// ec.europa.eu/digital-single-market/en/news/proposal-directive-european -parliament-and-council-copyright-digital-single-market.

European Commission. (2017). Digital single market. Retrieved September 7, 2018, from https://ec.europa.eu/commission/priorities/digital-single-mar ket_en.

European Parliament and The Council. (2001). Directive 2000/31/EC of the European parliament and of the Council of 8 June 2000 on certain legal aspects of information society services, in particular electronic commerce, in the Internal Market ('Directive on electronic commerce'), Official Journal of the European Communities, L. 178, 1-16.

Gawer, A. (Ed.). (2009). Platforms, markets and innovation. Cheltenham, United Kingdom: Edward Elgar. DOI: https://doi.org/10.4337/9781849803311.

Goudin, P. \& European Added Value Unit. (2016). The cost of non-Europe in the sharing economy: economic, social and legal challenges and opportunities. Brussels, Belgium: European Union. Retrieved September 7, 2018, from http://bookshop.europa.eu/uri?target=EUB:NOTICE:QA0116059:EN:H TML.

Hamilakis, Y. (2007). The nation and its ruins: Antiquity, archaeology, and national imagination in Greece. Oxford, United Kingdom: Oxford University Press.

Hamilakis, Y. (2013). Archaeology and the senses: Human experience, memory, and affect. Cambridge, United Kingdom: Cambridge University Press.

Harman, G. (2018). Object-oriented ontology: A new theory of everything. London, United Kingdom: Pelican.

Latour, B. (1996). Aramis, or the love of technology. Cambridge, MA: Harvard University Press.

Law 3028/2002. On the protection of antiquities and cultural heritage in general. Retrieved November 20, 2019, from https://www.bsa.ac.uk/wp-content /uploads/2018/11/Archaeological-Law-3028-2002.pdf. 
Lessig, L. (1996). The zones of cyberspace. Stanford Law Review, 48(May), 1403-1411.

Lessig, L. (1998). The new Chicago school. The Journal of Legal Studies, 27(S2), 661-691.

Lessig, L. (1999). Code and other laws of cyberspace. New York, NY: Basic Books. Manovich, L. (2001). The language of new media. Cambridge, MA: MIT Press. McLuhan, M. (1994). Understanding media: The extensions of man. Cambridge, MA: MIT Press.

Morando, F. \& Tsiavos, P. (2011). Diritti sui beni culturali e licenze libere (ovvero, di come un decreto ministeriale può far sparire il pubblico dominio in un paese). Retrieved September 7, 2018, from https://www.researchgate.net /publication/256034821_Diritti_sui_beni_culturali_e_licenze_libere _ovvero_di_come_un_decreto_ministeriale_puo_far_sparire_il_pubblico _dominio_in_un_paese_Cultural_Heritage_Rights_and_Open_Licenses _ie_How_a_Ministerial_Decre.

Orlikowski, W. J. \& Scott, S. V. (2008). Sociomateriality: Challenging the separation oftechnology, workandorganization. The Academyof Management Annals, 2(1), 433-474. DOI: https://doi.org/10.5465/19416520802211644.

Partnership Agreement. (2016, February 22). Partnership Agreement (PA) 2014-2020. Retrieved September 7, 2018, from https://www.espa.gr/en /Pages/staticPartnershipAgreement.aspx.

Schmidgen, H. (2014). Bruno Latour in pieces: An intellectual biography. New York, NY: Fordham University Press.

Scott, S. V. \& Orlikowski, W. J. (2013). Sociomateriality - taking the wrong turning?: A response to Mutch. Information and Organization, 23(2), 77-80. DOI: https://doi.org/10.1016/j.infoandorg.2013.02.003.

Surowiecki, J. (2005). The wisdom of crowds. Washington, DC: Anchor.

Szegedy-Maszak, A. (2001). Felix Bonfils and the traveller's trail through Athens. History of Photography, 25(1), 13-43. DOI: https://doi.org/10.1080 /03087298.2001.10443433.

Winner, L. (1993). Upon opening the black box and finding it empty: Social constructivism and the philosophy of technology. Science, Technology, \& Human Values, 18(3), 362-378. 